\title{
Drug addiction stigma in relation to methadone maintenance treatment by different service delivery models in Vietnam
}

Bach Xuan Tran ${ }^{1,2^{*}}$, Phuong Bich Vu', Long Hoang Nguyen ${ }^{1,3}$, Sophia Knowlton Latkin ${ }^{4}$, Cuong Tat Nguyen ${ }^{5}$, Huong Thu Thi Phan ${ }^{6}$ and Carl A. Latkin²

\begin{abstract}
Background: The rapid expansion of methadone maintenance treatment (MMT) services has significantly improved health status and quality of life of patients. However, little is known about its impacts on addiction-related stigma and associated factors.

Methods: A cross-sectional survey was conducted in 2013 in Vietnam's capital, Hanoi, and Nam Dinh province among 1016 methadone maintenance patients; $26.6 \%$ at provincial AIDS centers (PAC) and $73.4 \%$ at district health centers (DHC), respectively. Drug addiction history and related stigma, health status, MMT-related covariates, and sociodemographic characteristics were interviewed.

Results: More than one-sixth of the sample reported experiencing felt or enacted stigma, including Blame or Judgement (17.2\%), Shame (19.9\%), or Others' fear of HIV transmission (17.1\%). These proportions were higher in PACs than in DHCs, which are integrated with other HIV or general health care services. Very few patients reported being discriminated at the workplace $(2.5 \%)$ or at health care services $(1.7 \%)$; however, $15.6 \%$ of patients at PACs and $10.6 \%$ of patients at DHCs reported discrimination in their communities. Drug users taking MMT for longer periods were less likely to report felt stigma. Other factors associated with stigma against MMT patients included the lack of comprehensive services, higher education, presence of pain/discomfort, and anxiety/ depression, self-reported HIV positive, and number of previous drug rehabilitation episodes.

Conclusion: The study shows a high level of stigma against MMT patients and emphasizes the necessity to integrate MMT with comprehensive health and support services. Mass communication campaigns to reduce stigma against people with drug addiction and HIV/AIDS, as well as vocational trainings and jobs referrals for MMT patients, are needed to maximize the benefits of MMT programs in Vietnam.
\end{abstract}

Keywords: Stigma, Drug addiction, Methadone maintenance treatment

\footnotetext{
* Correspondence: bach@hmu.edu.vn

'Institute for Preventive Medicine and Public Health, Hanoi Medical

University, Hanoi, vietnam

${ }^{2}$ Department of Health, Behavior and Society, Johns Hopkins Bloomberg

School of Public Health, Baltimore, MD, USA

Full list of author information is available at the end of the article
} 


\section{Background}

Illicit drug use has been recognized as a major global public health issue and continues to drive HIV epidemics in various low and middle-income countries. In 2013, an estimation of 213 million people still used illicit drugs, with 27 million having health problems and approximately 1.65 million living with HIV making it one of the leading attributable factors to the global burden of disease [1]. In Vietnam, along with sex workers, people who inject drugs (PWID) have been labelled "social evils" due to their high prevalence of perceived immoral behaviors such as criminal activities or deteriorating health, which could threaten the safety of the population [2,3].

Methadone is a highly effective medication for opioid dependence [4] and methadone maintenance treatment (MMT) has been found to improve health status and promote access to health care among drug users [5-7]. Moreover, MMT helps to reduce the frequency of illicit drug use [7-9], HIV-related risk behaviors [10, 11] and illegal activities [12, 13]. Expanding the coverage of MMT has a major role as a cost-effective strategy in planning HIV/AIDS prevention and control programs in both lower and upper-income countries [7, 14, 15].

However, drug users might confront stigmatization even when they enroll in MMT programs [14]. Those infected with HIV/AIDS may suffer from drug use and HIV stigma. Discrimination may occur at multiple locations, such as health care facilities and family, community, or work places. For example, a study of Ahern et al. showed that $75.2 \%$ of drug users experienced discrimination in their family [16]. Stigma attached to drug use has been found to have negative effects on the health status of drug users and to hinder treatment adherence and health improvement $[14,17,18]$. Therefore, understanding influential factors and identifying strategies to reduce drug addiction-related stigma are essential for maximizing the effectiveness of MMT programs.

In Vietnam, PWID are one of the most-at-risk populations and account for about a half of the total number of people living with HIV/AIDS [6]. To respond, the government of Vietnam has developed comprehensive HIV/AIDS policies and programs, including a plan for expanding MMT programs to 80,000 drug users [19]. In 2015, there were only 170 MMT clinics nationwide with 31,200 patients $[20,21]$. MMT service has been delivered in stand-alone or integrative models, which are colocated or managed with other HIV-related or general health care services. The MMT services are organized with trained specialists and standardized facilities following national guidelines established by the Vietnam Ministry of Health. There have been studies that examined the experiences of MMT patients and sources of stigma $[14,22-24]$ as well as the role of services providers. Very few studies, however, have focused on different service delivery models or have been conducted in the context of a large drug injection-related HIV epidemic. This study examines the differences in levels of felt and enacted stigma that MMT patients may experience across different service delivery models and levels of health administration.

\section{Methods}

\section{Survey design and sampling}

A cross-sectional survey was performed from June to August 2013 in Hanoi and Nam Dinh provinces. There were five MMT clinics involved, four of which were located at district health centres (DHC), namely Tu Liem, Ha Dong, Long Bien, and Xuan Truong, and one clinic was at Nam Dinh Provincial AIDS Center (PAC). The characteristics of study sites are listed in Table 1 . We selected the two provinces in consultation with program managers at the Vietnam Authority of HIV/AIDS for a purposive comparison of an experienced setting, Hanoi, and a new setting, Nam Dinh Province. The MMT sites were primarily selected for the comparison of various service delivery models in different level of health administration. In general, drug users register at the nearest MMT clinics and these clinics provide treatment regardless of patients' HIV status. In the organization of Vietnam's health services delivery system, the regional polyclinic is providing primary health care for an area that combines several communes and is linked to commune health stations $[25,26]$. Therefore, the criteria for enrolling drug users in selected MMT were indifferent.

Eligibility criteria for recruiting participants included: 1) taking or initiating MMT in selected sites; 2) presenting at clinics during study periods; 3 ) being 18 years old or above; 4) having the capacity to answer questionnaire within $20 \mathrm{~min}$ and 5) agreeing to participate. A convenient sampling technique was used to enroll a total of

Table 1 Study settings and sample size

\begin{tabular}{llll}
\hline Level & Settings & Site Name & Type of services \\
\hline Province & Nam Dinh City & Provincial AIDS Center & MMT+ VCT \\
District (rural) & Xuan Truong District & District Health Center & MMT+VCT+ART+GH \\
District (urban) & Tu Liem District & District Health Center & MMT+VCT+ART+GH \\
District (urban) & Long Bien District & District Health Center & MMT+VCT+ART+GH \\
District (urban) & Ha Dong District & Regional Polyclinic & MMT+ GH \\
\hline
\end{tabular}


1016 patients in this study. Patients were invited into a designated room for face-to-face interviewing. Before the interview, participants were introduced to the study and asked to provide written informed consent. The response rate was $80-90 \%$ across sites. Interviewers were master's students of public health at Hanoi Medical University. The students were working in HIV study and had no affiliation with the clinics in which they invited patients to participate.

\section{Measures and instruments}

A structured questionnaire was developed to use in this study. Data on socioeconomic characteristics, drug use behaviors, HIV status was interviewed. Drug use information included age at initial drug use, time since first drug injection, times of previous drug rehabilitation, and duration of MMT treatment. Health status of respondents was measured in five dimensions (mobility, self-care, usual activities, pain/discomfort, and anxiety/ depression) using the five-level EQ-5D (EQ-5D-5 L) instrument that has been validated and widely used in Vietnamese populations [6, 27, 28]. Responses were then recorded to the EQ-5D dimensions as either having any health problems or no problems.

It has been well-documented that the stigma against HIV and drug use in Vietnam has been fueled by both the fear of HIV infection and social values and by judgements on addiction and other risk behaviours [3, 18, 29-32]. In some settings that contain large drug-using populations with generalized HIV epidemics, the stigma and discrimination against HIV/AIDS and addiction are intertwined $[3,33,34]$. We referred to the Substance Abuse SelfStigma Scale by Luoma and measures of HIV-related stigma $[35,36]$. In addition, we adapted the conceptual framework by Parker and Aggleton to construct the measure of drug addiction-related stigma among MMT patients [37]. We then piloted the measures in drug users and people living with HIV/AIDS. The final measure of stigma included five dimensions: (1)Blame/Judgement, (2) Shame, (3) Discrimination in various settings (work place, health care services, family, and community), (4) Disclosure of addiction or health status (including HIV-positive if seropositive), and (5) Other's fear of HIV transmission among those patients who self-reported being HIVpositive [36]. Respondents were asked if they had experienced any of the above types of stigma within the last month. The measure, for example, included the following questions with the response options: Yes/No/Not answer.

1. In general, have you recently been blamed or criticized because of your health status and drug use behaviors?

2. Do you currently feel shame because of your health status and drug use behaviors?
3. Have you felt discriminated against or treated badly by others? In which circumstances (work place/all health facilities/family/community/others)?.

4. Have you ever disclosed your health status and drug use behaviors with others? With whom did you share?

5. (For HIV positives) Has anyone expressed fear of contracting HIV from casual contacts with you?

\section{Statistical analysis}

$T$-test and $\mathrm{X}^{2}$ tests were used to compare differences of characteristics among different services models. Multivariate logistic regression was employed to determine the associated factors with self-stigma, discrimination, and disclosure. In this study, a stepwise backward selection strategy was applied along with multivariate regression to have reduced models. This strategy used threshold with the log-likelihood ratio test to have predictors with $p$-values of $<0.1$ included.

\section{Ethics, consent and permissions}

The protocol of this study was reviewed and approved by the Vietnam Authority of HIV/AIDS Control's Scientific Research Committee. Written informed consent was obtained from all participants. Patients could withdraw at any time without the influence on their current treatment.

\section{Results}

In total, 1016 patients participated in this study; 746 were receiving MMT at one of four DHCs, and 270 others were receiving MMT at Nam Dinh PAC. Among those, $98.7 \%$ were male and the mean age was 36.8 years $(\mathrm{SD}=7.7)$. The majority lived with a spouse or partner $(67.7 \%)$ and had high school education or below (93.4\%). The percentage of patients who were currently working was $74.6 \%$, and of these, $53.4 \%$ were selfemployed, $9.8 \%$ were workers or farmers, and $11.4 \%$ had other jobs (white collars, students, and other) (Table 2).

Table 3 presents health status, history of drug addiction, and MMT utilization of participants. The average age of drug use initiation was 24.5 years $(\mathrm{SD}=6.7$ ), corresponding to an average duration of drugs use of 13.3 years $(\mathrm{SD}=5.9)$ and drug injection duration of 10.2 years $(\mathrm{SD}=4.9)$. Enrolled patients experienced approximately 5 episodes $($ mean $=4.8)$ of drug rehabilitation prior to MMT. The duration of MMT utilization was 16.5 months on average $(\mathrm{SD}=11.0)$; patients from PAC experienced an average of 11.4 months $(\mathrm{SD}=7.2)$ while patients from DHC had undergone a longer duration on MMT (mean = 18.4 months, SD =11.5). Regarding health status of patients, we found homogeneity in outcomes between provincial and district health facilities, except a higher prevalence of pain or discomfort 
Table 2 Socioeconomic characteristics of MMT patients by level of health services administration

\begin{tabular}{|c|c|c|c|c|c|c|c|}
\hline & \multicolumn{2}{|c|}{ Provincial } & \multicolumn{2}{|c|}{ District } & \multicolumn{2}{|l|}{ All } & \multirow[t]{2}{*}{$p$-value } \\
\hline & Mean & SD & Mean & SD & Mean & SD & \\
\hline \multirow[t]{2}{*}{ Age } & 36.8 & 7.7 & 36.8 & 7.7 & 36.8 & 7.6 & 0.52 \\
\hline & $\mathrm{N}$ & $\%$ & $\mathrm{~N}$ & $\%$ & $\mathrm{~N}$ & $\%$ & \\
\hline Sex (Male) & 266 & 98.5 & 737 & 98.8 & 1003 & 98.7 & 0.73 \\
\hline \multicolumn{8}{|c|}{ Educational attainment } \\
\hline Illiterate & 4 & 1.5 & 13 & 1.7 & 17 & 1.7 & 0.03 \\
\hline Elementary & 21 & 7.8 & 98 & 13.1 & 119 & 11.7 & \\
\hline Secondary & 103 & 38.2 & 323 & 43.3 & 426 & 41.9 & \\
\hline High & 121 & 44.8 & 266 & 35.7 & 387 & 38.1 & \\
\hline Vocational & 12 & 4.4 & 20 & 2.7 & 32 & 3.2 & \\
\hline University & 9 & 3.3 & 26 & 3.5 & 35 & 3.4 & \\
\hline \multicolumn{8}{|l|}{ Marital status } \\
\hline Single & 101 & 37.4 & 150 & 20.1 & 251 & 24.7 & $<0.01$ \\
\hline $\begin{array}{l}\text { Live with } \\
\text { spouse }\end{array}$ & 148 & 54.8 & 537 & 72.0 & 685 & 67.4 & \\
\hline Live with partner & 0 & 0.0 & 3 & 0.4 & 3 & 0.3 & \\
\hline Divorced & 19 & 7.0 & 53 & 7.1 & 72 & 7.1 & \\
\hline Widow & 2 & 0.7 & 3 & 0.4 & 5 & 0.5 & \\
\hline \multicolumn{8}{|l|}{ Religion } \\
\hline $\begin{array}{l}\text { Cult of } \\
\text { ancestors }\end{array}$ & 247 & 91.5 & 649 & 87.0 & 896 & 88.2 & 0.17 \\
\hline Buddhism & 13 & 4.8 & 46 & 6.2 & 59 & 5.8 & \\
\hline Catholic & 10 & 3.7 & 46 & 6.2 & 56 & 5.5 & \\
\hline Protestant & 0 & 0.0 & 5 & 0.7 & 5 & 0.5 & \\
\hline \multicolumn{8}{|l|}{ Employment } \\
\hline Unemployed & 76 & 28.2 & 183 & 24.5 & 259 & 25.5 & $<0.01$ \\
\hline Self-employed & 159 & 58.9 & 383 & 51.3 & 542 & 53.4 & \\
\hline White collars & 5 & 1.9 & 17 & 2.3 & 22 & 2.2 & \\
\hline Workers, Farmers & 10 & 3.7 & 90 & 12.1 & 100 & 9.8 & \\
\hline Students & 0 & 0.0 & 2 & 0.3 & 2 & 0.2 & \\
\hline Other jobs & 20 & 7.4 & 71 & 9.5 & 91 & 9.0 & \\
\hline
\end{tabular}

among patients at DHCs. The prevalence of patients who reported any health problem was highest in the anxiety/depression dimension (20.7\%), followed by pain/discomfort (19.2\%).4.8\% of patients reported concurrent drug use during MMT and the percentage of self-reported positive HIV status was $8.1 \%$.

In Table 4, the proportion of stigma and discrimination among MMT patients is shown. More than one-sixth of the sample population reported experiencing different types of stigma or discrimination related to their addiction or health status, including Blame/Judgement (17.2\%), Shame (19.9\%), or Fear of HIV transmission by others (17.1\%); these percentages were higher in PAC than in DHCs. There were very few patients who reported discrimination at the workplace $(2.5 \%)$ or at health care services (1.7\%); however, $15.6 \%$ patients at PAC and $10.6 \%$ patients at DHCs reported discrimination from their communities. The proportion of respondents who disclosed their addiction or health status to others was low (with spouse $(58.3 \%)$, parents $(50.4 \%)$, health workers (37.3\%), and peer educators $(14.3 \%)$ ). Patients who were taking MMT at DHCs reported less discrimination and more disclosure of their status to others.

Table 5 presents the factors that are associated with stigma and discrimination against drug users. Drug users taking MMT for longer periods were less likely to report being blamed or judged ( $\mathrm{OR}=0.98,95 \% \mathrm{CI}=0.97-0.99$ ), but they were also less likely to disclose their health condition to others $(\mathrm{OR}=0.96,95 \% \mathrm{CI}=0.95-0.98)$. A higher likelihood of disclosing health conditions was associated with people living with a spouse $(\mathrm{OR}=1.56,95 \%$ $\mathrm{CI}=1.14-2.15)$ versus patients living alone. Other factors that contributed to perceived stigma and discrimination among MMT patients included higher education, presence of pain/discomfort and anxiety/depression, selfreported HIV positive, and number of previous drug rehabilitation episodes. Moreover, these factors also increased the likelihood of disclosing addiction and any health problem among MMT patients.

\section{Discussion}

To date, this is the first study comparing drug addictionrelated stigma among MMT patients across different service delivery models and levels of administration. The findings showed that though MMT has been known to improve health behaviors among drug users, a high proportion of users suffered from stigma and discrimination due to their previous drug addiction or health status. Although felt stigma decreased among patients who were enrolled in MMT for longer periods and discrimination was rarely seen in health facilities, workplace, and family life, felt stigma remained high in communities where patients live, especially in urban areas and in areas of higher level of health care service administration.

\section{Stigma in relation to MMT and different service delivery models}

Our findings highlight the encouraging progress in quality improvement and stigma reduction in HIV-related health care services in Vietnam. Previously, stigma was commonly reported in health care services, which reduced the access and use of health care and support services among people with HIV/AIDS [18], and was burdensome to health workers in HIV facilities [30]. In this study, just about $2 \%$ of respondents reported experiencing any discrimination at health care services. Meanwhile, the high level of discrimination from communities against drug users is consistent with a previous 
Table 3 Health status and history of drug addiction and MMT

\begin{tabular}{|c|c|c|c|c|c|c|c|}
\hline & \multicolumn{2}{|c|}{ Provincial } & \multicolumn{2}{|c|}{ District } & \multicolumn{2}{|l|}{ All } & \multirow[t]{2}{*}{$p$-value } \\
\hline & Mean & SD & Mean & SD & Mean & SD & \\
\hline Age at first drug use & 24.3 & 7.0 & 24.6 & 6.7 & 24.5 & 6.7 & 0.10 \\
\hline Time since 1st drug use (yr.) & 13.5 & 5.1 & 13.2 & 6.1 & 13.3 & 5.9 & 0.07 \\
\hline Time since 1st drug inject(yr.) & 10.9 & 4.4 & 9.9 & 5.1 & 10.2 & 4.9 & 0.12 \\
\hline \# previous drug rehabilitation episodes & 5.7 & 7.2 & 4.5 & 5.9 & 4.8 & 6.3 & $<0.01$ \\
\hline \multirow[t]{2}{*}{ Duration on MMT (month) } & 11.4 & 7.2 & 18.4 & 11.5 & 16.5 & 11.0 & $<0.01$ \\
\hline & N & $\%$ & $\mathrm{~N}$ & $\%$ & N & $\%$ & \\
\hline \multicolumn{8}{|l|}{ Self-reported health problems } \\
\hline Mobility & 19 & 7.04 & 55 & 7.37 & 74 & 7.28 & 0.86 \\
\hline Self-care & 10 & 3.7 & 30 & 4.02 & 40 & 3.94 & 0.82 \\
\hline Usual Activities & 18 & 6.67 & 42 & 5.63 & 60 & 5.91 & 0.54 \\
\hline Pain or Discomfort & 37 & 13.7 & 143 & 19.17 & 180 & 17.72 & 0.04 \\
\hline Anxiety or Depression & 56 & 20.74 & 154 & 20.64 & 210 & 20.67 & 0.97 \\
\hline Concurrent drug use & 15 & 5.56 & 34 & 4.56 & 49 & 4.82 & 0.51 \\
\hline History of drug injection & 222 & 82.22 & 524 & 70.24 & 746 & 73.43 & $<0.01$ \\
\hline Self-reported HIV status & & 0 & & 0 & & 0 & \\
\hline Negative & 239 & 88.52 & 637 & 85.39 & 876 & 86.22 & 0.15 \\
\hline Positive & 22 & 8.15 & 60 & 8.04 & 82 & 8.07 & \\
\hline N/A & 9 & 3.33 & 49 & 6.57 & 58 & 5.71 & \\
\hline
\end{tabular}

qualitative analysis in Thai Nguyen Province by Rudolph et al. [31] In addition to previous studies, we found that not only socioeconomic status and history of drug rehabilitation significantly predicted stigma and discrimination among drug users taking MMT, but also other

Table 4 Proportion of stigma and discrimination among MMT patients

\begin{tabular}{|c|c|c|c|c|c|c|c|}
\hline & \multicolumn{2}{|c|}{ Provincial } & \multicolumn{2}{|c|}{ District } & \multicolumn{2}{|l|}{ All } & \multirow[t]{2}{*}{$p$-value } \\
\hline & $\mathrm{N}$ & $\%$ & $\mathrm{~N}$ & $\%$ & $\mathrm{~N}$ & $\%$ & \\
\hline 1. Blame, judge & 46 & 19.7 & 119 & 16.4 & 165 & 17.2 & 0.25 \\
\hline 2. Shame & 66 & 28.5 & 124 & 17.2 & 190 & 19.9 & $<0.01$ \\
\hline \multicolumn{8}{|l|}{ 3. Discrimination } \\
\hline Work place & 12 & 4.4 & 13 & 1.7 & 25 & 2.5 & 0.01 \\
\hline Health care services & 9 & 3.3 & 8 & 1.1 & 17 & 1.7 & 0.01 \\
\hline Family & 8 & 3.0 & 16 & 2.1 & 24 & 2.4 & 0.45 \\
\hline Community & 42 & 15.6 & 79 & 10.6 & 121 & 11.9 & 0.03 \\
\hline \multicolumn{8}{|l|}{ 4. Disclosure } \\
\hline Spouse & 109 & 40.4 & 483 & 64.8 & 592 & 58.3 & $<0.01$ \\
\hline Parents & 133 & 49.3 & 379 & 50.8 & 512 & 50.4 & 0.66 \\
\hline Relatives & 53 & 19.6 & 229 & 30.7 & 282 & 27.8 & $<0.01$ \\
\hline Friends & 59 & 21.9 & 237 & 31.8 & 296 & 29.1 & $<0.01$ \\
\hline Health workers & 72 & 26.7 & 307 & 41.2 & 379 & 37.3 & $<0.01$ \\
\hline Peer educators & 38 & 14.1 & 107 & 14.3 & 145 & 14.3 & 0.91 \\
\hline 5. Others' fears of HIV & 5 & 22.7 & 9 & 15.0 & 14 & 17.1 & 0.41 \\
\hline
\end{tabular}

major factors included health status and the availability of comprehensive HIV/AIDS and general health care services.

In Vietnam, a DHC is the closest health care facility providing methadone medication for drug dependence treatment. In this study, patients at DHCs or regional polyclinics were less likely to be stigmatized compared to those at PAC. One study by Mukora et al. showed that patients were concerned about stigma and loss of privacy if they received treatment in decentralized clinics [38]. However, a study by Odeny et al. found that decentralized HIV-related services that were integrated into primary health care did not worsen stigma [39]. The differences in patients' preferences and perceived stigma highlighted the importance of understanding contextual factors and stages of the epidemics in each setting. In this study, fewer patients felt ashamed or experienced discrimination at MMT clinics with other HIV-related and general health care services; nonetheless, these results may not apply to those living in rural areas.

In addition, we found that drug users taking MMT for longer periods of time felt less blamed or judged $(\mathrm{OR}=0.98,95 \% \mathrm{CI}=0.97-0.99)$. This may be due to the effects of MMT on the improvement of health status and the reduction of risk behaviors and illegal activities, which may promote positive attitudes of family and others toward MMT patients. Previous studies have shown that MMT patients improved substantially 
Table 5 Factors associated with stigma and discrimination against drug users

\begin{tabular}{|c|c|c|c|c|c|c|c|c|c|c|c|c|}
\hline \multirow{3}{*}{ Duration on MMT (months) } & \multicolumn{3}{|c|}{ Blame, judge } & \multicolumn{3}{|c|}{ Shame } & \multicolumn{3}{|c|}{ Discrimination } & \multicolumn{3}{|c|}{ Disclosure of addiction or health status } \\
\hline & \multirow{2}{*}{$\frac{\mathrm{OR}}{0.98^{\mathrm{a}}}$} & \multicolumn{2}{|l|}{$95 \mathrm{Cl}$} & \multirow{2}{*}{$\begin{array}{l}\text { OR } \\
1.00\end{array}$} & \multicolumn{2}{|l|}{$95 \mathrm{Cl}$} & \multirow{2}{*}{$\frac{\text { OR }}{0.99}$} & \multicolumn{2}{|c|}{$95 \mathrm{Cl}$} & \multirow{2}{*}{$\begin{array}{l}\mathrm{OR} \\
0.96^{\mathrm{a}}\end{array}$} & \multicolumn{2}{|c|}{$95 \mathrm{Cl}$} \\
\hline & & 0.97 & 0.99 & & 0.98 & 1.02 & & 0.96 & 1.01 & & 0.95 & 0.98 \\
\hline \multicolumn{13}{|l|}{ MMT model (MMT+ PAC - ref) } \\
\hline Rural MMT-ART-VCT-DGH & 1.67 & 0.99 & 2.82 & & & & & & & & & \\
\hline Urban MMT-ART-VCT-DGH & & & & $0.36^{\mathrm{a}}$ & 0.22 & 0.58 & $0.51^{a}$ & 0.31 & 0.84 & $3.21^{\mathrm{a}}$ & 2.13 & 4.83 \\
\hline MMT + Regional poly clinic & & & & $0.39^{a}$ & 0.24 & 0.63 & & & & & & \\
\hline \multicolumn{13}{|c|}{ Education (High school or Lower - ref) } \\
\hline College/University & 1.82 & 0.93 & 3.57 & & & & $1.96^{\mathrm{a}}$ & 1.02 & 3.74 & & & \\
\hline \multicolumn{13}{|l|}{ Marital status } \\
\hline Live with spouse vs. Single & & & & & & & & & & $1.56^{\mathrm{a}}$ & 1.14 & 2.15 \\
\hline \multicolumn{13}{|l|}{ Religion } \\
\hline Buddhism vs. Cult of ancestors & 0.43 & 0.15 & 1.22 & & & & & & & & & \\
\hline \multicolumn{13}{|l|}{ Employment (Unemployed - ref) } \\
\hline Self-employed & 0.72 & 0.49 & 1.04 & & & & & & & & & \\
\hline White collars & 0.30 & 0.06 & 1.44 & & & & & & & & & \\
\hline Workers, Farmers & $0.42^{\mathrm{a}}$ & 0.19 & 0.93 & $0.50^{\mathrm{a}}$ & 0.25 & 0.99 & 0.52 & 0.24 & 1.13 & $0.49^{a}$ & 0.30 & 0.80 \\
\hline Other jobs & & & & 1.65 & 0.93 & 2.95 & & & & & & \\
\hline \multicolumn{13}{|l|}{ Self-reported health problems } \\
\hline Mobility & & & & 1.82 & 1.00 & 3.31 & & & & $0.39^{a}$ & 0.20 & 0.74 \\
\hline Self-care & & & & & & & 2.12 & 0.94 & 4.81 & & & \\
\hline Usual Activities & & & & & & & & & & 2.22 & 0.90 & 5.47 \\
\hline Pain or Discomfort & & & & & & & & & & $2.01^{\mathrm{a}}$ & 1.16 & 3.47 \\
\hline Anxiety or Depression & $1.79^{\mathrm{a}}$ & 1.19 & 2.70 & $2.39^{a}$ & 1.62 & 3.53 & 1.49 & 0.95 & 2.32 & $1.66^{\mathrm{a}}$ & 1.02 & 2.69 \\
\hline \multicolumn{13}{|c|}{ Self-reported HIV status (Negative - ref) } \\
\hline Positive & & & & $1.74^{a}$ & 1.01 & 3.04 & & & & & & \\
\hline N/A & & & & & & & $2.15^{\mathrm{a}}$ & 1.04 & 4.47 & & & \\
\hline \multicolumn{13}{|c|}{ \# previous drug rehabilitation (None - ref) } \\
\hline $1-5$ times & 2.27 & 0.88 & 5.88 & & & & 0.73 & 0.49 & 1.08 & $1.86^{\mathrm{a}}$ & 1.21 & 2.86 \\
\hline $6-10$ times & $2.89^{a}$ & 1.07 & 7.80 & & & & & & & $1.73^{\mathrm{a}}$ & 1.03 & 2.89 \\
\hline$>10$ times & 2.75 & 0.85 & 8.83 & & & & & & & & & \\
\hline Ever inject drug vs. None & & & & & & & 1.53 & 0.94 & 2.48 & & & \\
\hline Concurrent drug use vs. None & & & & & & & $2.44^{\mathrm{a}}$ & 1.11 & 5.37 & & & \\
\hline
\end{tabular}

${ }^{a}$ significant at $5 \%$ level

in physical health; however, the changes in mental and social status were moderate and small, respectively [7, 40]. Participants reporting anxiety and depression were also much more likely to report feeling blamed/judged and shame. In addition, drug users who currently used drugs during MMT were more likely to suffer from discrimination than those who did not. Collectively, these results indicated the importance of maintaining MMT to reduce drug use behaviors, as well as the importance of providing comprehensive mental health care for patients.

The study also suggests that the use of MMT is preferred more than traditional drug rehabilitation in Vietnam. Less effective drug rehabilitation was significantly associated with higher stigma. Drug detoxification is available in Vietnam [6]' but with high episodes of failure rehabilitation, patients may believe that they cannot be successfully treated, and therefore, blame themselves for relapsing. In this study, the proportion of felt stigma was lower than in other settings. This coincides with findings from previous studies that MMT helps improve social and economic status of patients and their families [5, 7, 40-42].

Notably, the proportion of MMT patients' felt stigma in communities was significantly higher than in families, health facilities, or workplaces. This result suggested that although participating in MMT program could reduce stigma in those latter place, stigma remained a great 
barrier for MMT patients trying to reenter into their community. A study conducted by Tomori et al. in Vietnam showed that even when a person successfully detoxifies from illicit drugs, they had to confront the drug-related stigmatization in their community [2]. Therefore, mass media campaigns are necessary to reduce stigma against people with HIV/AIDS and history of drug addiction in settings with large drug injection related HIV epidemics.

In this study, we also found that patients who were HIV positive or unknown status were more likely to report self-stigmatization. Literature suggests that drug users report shameful attitudes and think that HIV might be a punishment for their past [2]. On the other hand, it is noteworthy to find that people who were employed were less likely to feel self-stigmatization. Vocational training and job referrals should be considered in local planning to maximize the benefits of MMT programs.

\section{Disclosing MMT patients' status}

Disclosure of status among HIV-positive people and PWID has been considered a potential method to reduce the spread of HIV/AIDS. Although the drawbacks of self-disclosure may include stigma, loss of privacy, and blame, it may help those high-risk populations to reduce HIV risk behaviors and increase access to HIV-related care, as well as being related to better adherence for those receiving treatment [18]. In present study, patients receiving MMT at DHC reported a higher percentage of disclosing their condition to spouses, relatives, health workers, and friends than patients at PAC. This association can be partially explained by the fact that in order to hide their conditions and avoid discrimination, drug users tended to receive treatment at a health center far from their hometowns [43].

People taking MMT in long duration were less likely to disclose their health status to other people. There may several reasons be for this finding. First, as we observed, with the improvement in health status due to long duration of treatment, MMT patients might feel confident about their health and therefore may think that they do not need to share their status with other people. Second, information about MMT patients' treatment or their past may be used against them at work or in the community [44].

Most patients shared their status with their spouse $(58.3 \%)$ and parents $(50.4 \%)$, who were the closest relatives of patients. People living with a spouse also were likely to disclose. Families are a critical source of financial, physical, and emotional supports, which facilitate re-entry into the community for drug users [45]. Therefore, support from family has a central role in encouraging patients' disclosure.

\section{Implications}

There were several implications that can be drawn from this study. First, MMT clinics should be integrated with other health services and decentralized as satellite model to provide patients with accessible and friendly health care, which in turn may reduce stigma of patients. Strategies to optimize the effectiveness of this model should be considered for the scale-up plan of MMT programs. Second, mass media campaigns in television or on the internet should be conducted to reduce stigmatization in the community for MMT patients. Third, the role of parents/spouses should be heightened to help combat difficulties encountered when patients participate in MMT treatment. Lastly, physical and mental health conditions of patients should be acknowledged and addressed.

\section{Limitations}

Several limitations in this study should be under consideration. First, this cross-sectional design could not establish causal relation between stigma outcomes and MMT delivery models. In addition, a qualitative study should be conducted to understand how different models can impact on the feeling of stigma in accordance to patients' perceptions and experiences. Second, Self-report information may be subject to recall bias. Finally, the convenient sampling technique limited the generalization of this study.

\section{Conclusions}

In conclusion, the study highlighted significant higher levels of stigma among MMT patients at PAC as compared to people at DHC. The findings suggested the need to integrate MMT with the satellite model (DHC, regional poly-clinics, etc.) to reduce stigma. Moreover, the study emphasized the importance of maintaining MMT adherence and effectiveness and the importance of intervening on stigma amongst drug users, family, health care workers, and community.

\section{Availability of data and materials}

Data are available from the Authority of HIV/AIDS Control (VAAC). However, since the Government of Vietnam issued the Law on HIV/AIDS, information of HIV-affected people is confidential and cannot be shared. Requests for data on this study may be submitted to VAAC and go through a review process by the Scientific and Ethical Research Committee. The contact for requesting data use is Dr. Phan Thi Thu Huong, email huongphanmoh@gmail.com, Deputy Director in Research of the Vietnam Authority of HIV/AIDS Control, Ministry of Health, Vietnam.

Competing interests

The authors declare that they have no competing interests. 


\section{Authors' contributions}

BXT, CL and HTTP conceived of the study, and participated in its design. BXT, HTTP, LHN, CTN, CL, SKL and PBV implemented the survey and complied the data. LHN and BXT analyzed the data. BXT, LHN, HTTP, CTN, SKL and PBV helped to draft the manuscript. All authors read and approved the final manuscript.

\section{Author details}

'Institute for Preventive Medicine and Public Health, Hanoi Medical University, Hanoi, vietnam. ${ }^{2}$ Department of Health, Behavior and Society, Johns Hopkins Bloomberg School of Public Health, Baltimore, MD, USA. ${ }^{3}$ School of Medicine and Pharmacy, Vietnam National University, Hanoi, Vietnam. ${ }^{4}$ River Hill, Maryland, USA. ${ }^{5}$ Institute for Global Health Innovations, Duy Tan University, Da Nang, Vietnam. ${ }^{6}$ Authority of HIV/AIDS Control, Ministry of Health, Hanoi, Vietnam.

\section{Received: 28 August 2015 Accepted: 19 February 2016 Published online: 08 March 2016}

\section{References}

1. UNODC. World drug report 2015. New York: United Nations; 2015.

2. Tomori C, Go VF, le Tuan N, et al. "In their perception we are addicts": social vulnerabilities and sources of support for men released from drug treatment centers in Vietnam. Int J Drug Polic. 2014:25(5):897-904.

3. Lim T, Zelaya C, Latkin C, et al. Individual-level socioeconomic status and community-level inequality as determinants of stigma towards persons living with HIV who inject drugs in Thai Nguyen, Vietnam. J Int AIDS Soc. 2013;16(3 Suppl 2):18637

4. Peles E, Schreiber S, Adelson M. Trends in substance abuse and infectious disease over 20 years in a large methadone maintenance treatment (MMT) clinic in Israel, Substance abuse: official publication of the association for medical education and research in substance abuse. 2014.

5. Tran BX, Nguyen LT. Impact of methadone maintenance on health utility, health care utilization and expenditure in drug users with HIV/AIDS. Int $J$ Drug Polic. 2013;24(6):e105-110.

6. Tran BX. Willingness to pay for methadone maintenance treatment in Vietnamese epicentres of injection-drug-driven HIV infection. Bull World Health Organ. 2013;91(7):475-82.

7. Tran BX, Ohinmaa A, Duong AT, et al. Changes in drug use are associated with health-related quality of life improvements among methadone maintenance patients with HIV/AIDS. Qual Life Res. 2012;21(4):613-23.

8. Fareed A, Casarella J, Amar R, Vayalapalli S, Drexler K. Benefits of retention in methadone maintenance and chronic medical conditions as risk factors for premature death among older heroin addicts. J Psychiatr Pract. 2009;15(3):227-34

9. Simoens S, Matheson C, Bond C, Inkster K, Ludbrook A. The effectiveness of community maintenance with methadone or buprenorphine for treating opiate dependence. Br J Gen Pract. 2005:55(511):139-46.

10. Corsi KF, Lehman WK, Booth RE. The effect of methadone maintenance on positive outcomes for opiate injection drug users. J Subst Abus Treat. 2009;37(2):120-6.

11. Gowing $L$, Farrell $M$, Bornemann R, Sullivan $L$, Ali R. Substitution treatment of injecting opioid users for prevention of HIV infection. Cochrane Database Syst Rev. 2008;2:CD004145.

12. Lind B, Chen S, Weatherburn D, Mattick R. The effectiveness of methadone maintenance treatment in controlling crime: an Australian aggregate-level analysis. Br J Criminol. 2005;45(2):201-11.

13. Sheerin I, Green T, Sellman D, Adamson S, Deering D. Reduction in crime by drug users on a methadone maintenance therapy programme in New Zealand. N Z Med J. 2004;117(1190):U795.

14. Earnshaw V, Smith L, Copenhaver M. Drug addiction stigma in the context of methadone maintenance therapy: an investigation into understudied sources of stigma. Int J Ment Heal Addict. 2013;11(1):110-22.

15. Tran BX, Ohinmaa A, Duong AT, et al. Cost-effectiveness of methadone maintenance treatment for HIV-positive drug users in Vietnam. AIDS Care. 2012;24(3):283-90

16. Ahern J, Stuber J, Galea S. Stigma, discrimination and the health of illicit drug users. Drug Alcohol Depend. 2007:88(2-3):188-96.

17. Tran DA, Shakeshaft A, Ngo AD, et al. Structural barriers to timely initiation of antiretroviral treatment in Vietnam: findings from six outpatient clinics. PLoS One. 2012;7(12):e51289.
18. Thanh DC, Moland KM, Fylkesnes K. Persisting stigma reduces the utilisation of HIV-related care and support services in Viet Nam. BMC Health Serv Res. 2012;12:428

19. Tran BX, Ohinmaa A, Duong AT, et al. The cost-effectiveness and budget impact of Vietnam's methadone maintenance treatment programme in HIV prevention and treatment among injection drug users. Glob Public Health. 2012;7(10):1080-94.

20. Tran BX, Nguyen LH, Phan HT, Nguyen LK, Latkin CA. Preference of methadone maintenance patients for the integrative and decentralized service delivery models in Vietnam. Harm RedJ. 2015;12:29.

21. Tran BX, Nguyen LH, Phan HT, Latkin CA. Patient satisfaction with methadone maintenance treatment in Vietnam: a comparison of different integrative-service delivery models. PLoS One. 2015:10(11):e0142644.

22. Anstice S, Strike CJ, Brands B. Supervised methadone consumption: client issues and stigma. Subst Use Misuse. 2009:44(6):794-808.

23. Etesam F, Assarian F, Hosseini H, Ghoreishi FS. Stigma and its determinants among male drug dependents receiving methadone maintenance treatment. Arch Iran Med. 2014;17(2):108-14.

24. Olsen Y, Sharfstein JM. Confronting the stigma of opioid use disorder-and its treatment. JAMA. 2014;311(14):1393-4.

25. Nguyen TX, Tran BX, Arianna W, Christa H, Lars L. "Socialization of health care" in Vietnam: what is it and what are its pros and cons? Value in Health Regional Issues. 2014;3:24-6.

26. Tran BX, Van Hoang M, Nguyen HD. Factors associated with job satisfaction among commune health workers: implications for human resource policies. Global health action. 2013:6:1-6.

27. Tran BX, Ohinmaa A, Nguyen LT, Nguyen TA, Nguyen TH. Determinants of health-related quality of life in adults living with HIV in Vietnam. AIDS Care. 2011;23(10):1236-45.

28. Tran BX, Ohinmaa A, Nguyen LT. Quality of life profile and psychometric properties of the EQ-5D-5 L in HIV/AIDS patients. Health Qual Life Outcomes. 2012;10:132

29. Pulerwitz J, Oanh KT, Akinwolemiwa D, Ashburn K, Nyblade L. Improving hospital-based quality of care by reducing HIV-related stigma: evaluation results from Vietnam. AIDS Behav. 2015;19(2):246-56.

30. Ha PN, Chuc NT, Hien HT, Larsson M, Pharris A. HIV-related stigma: impact on healthcare workers in Vietnam. Glob Public Health. 2013;8 Suppl 1:S61-74.

31. Rudolph AE, Davis WW, Quan VM, et al. Perceptions of community- and family-level injection drug user (IDU)- and HIV-related stigma, disclosure decisions and experiences with layered stigma among HIV-positive IDUs in Vietnam. AIDS Care. 2012:24(2):239-44.

32. Pharris A, Hoa NP, Tishelman C, et al. Community patterns of stigma towards persons living with HIV: a population-based latent class analysis from rural Vietnam. BMC Public Health. 2011;11:705.

33. Lee SJ, Li L, Lin C, le Tuan A. Challenges facing HIV-positive persons who use drugs and their families in Vietnam. AIDS Care. 2015;27(3):283-7.

34. Van Tam V, Pharris A, Thorson A, Alfven T, Larsson M. "It is not that I forget, it's just that I don't want other people to know": barriers to and strategies for adherence to antiretroviral therapy among HIV patients in Northern Vietnam. AIDS Care. 2011;23(2):139-45.

35. Luoma JB, Nobles $\mathrm{RH}$, Drake $\mathrm{CE}$, et al. Self-stigma in substance abuse: development of a New measure. J Psychopathol Behav Assess. 2013;35(2):223-34

36. International Center for Research on Women. Can we measure HIV/AIDSrelated stigma and discrimination? Current knowledge about quantifying stigma in developing countries..Available at https://www.icrw.org/files/ publications/Can-We-Measure-HIV-Stigma-and-Discrimination.pdf. Accessed May 1, 2013. 2006

37. Parker R, Aggleton P. HIV and AIDS-related stigma and discrimination: a conceptual framework and implications for action. Soc Sci Med. 2003;57(1):13-24.

38. Mukora R, Charalambous S, Dahab M, Hamilton R, Karstaedt A. A study of patient attitudes towards decentralisation of HIV care in an urban clinic in South Africa. BMC Health Serv Res. 2011;11:205.

39. Odeny TA, Penner J, Lewis-Kulzer J, et al. Integration of HIV care with primary health care services: effect on patient satisfaction and stigma in rural Kenya. AIDS Res Treat. 2013;2013:10.

40. Tran BX, Ohinmaa A, Mills $\mathrm{S}$, et al. Multilevel predictors of concurrent opioid use during methadone maintenance treatment among drug users with HIV/AIDS. PLoS One. 2012:7(12):e51569.

41. Nguyen LT, Tran BX, Tran CT, Le HT, Tran SV. The cost of antiretroviral treatment service for patients with HIV/AIDS in a central outpatient clinic in Vietnam. CEOR. 2014;6:101-8. 
42. Tran BX, Duong AT, Nguyen LT, et al. Financial burden of health care for HIV/AIDS patients in Vietnam. Trop Med Int Health. 2013;18(2):212-8.

43. Nguyen NT, Keithly SC. A qualitative study on the sexual behaviour of people living with HIV in Vietnam. AIDS Care. 2012;24(7):921-8.

44. Murphy S, Irwin J. "Living with the dirty secret": problems of disclosure for methadone maintenance clients. J Psychoactive Drugs. 1992;24(3):257-64.

45. Kumar S, Mohanraj R, Rao D, Murray KR, Manhart LE. Positive coping strategies and HIV-related stigma in south India. AIDS Patient Care STDS. 2015;29(3):157-63.

Submit your next manuscript to BioMed Central and we will help you at every step:

- We accept pre-submission inquiries

- Our selector tool helps you to find the most relevant journal

- We provide round the clock customer support

- Convenient online submission

- Thorough peer review

- Inclusion in PubMed and all major indexing services

- Maximum visibility for your research

Submit your manuscript at www.biomedcentral.com/submit 